\title{
TECHNICAL AND ECONOMIC MODEL OF METALLURGICAL EQUIPMENT FOR OPTIMIZATION OF MAINTENANCE
}

\author{
Hana ŠPAČKOVÁ, Ivana BARČÁKOVÁ, Martin MENŠíK, Jaroslav SLÁČALA, Jiří DAVID, \\ Pavel ŠVEC \\ VSB - Technical University of Ostrava, Faculty of Materials Science and Technology, Ostrava, \\ Czech Republic,EU, hana.spackova@vsb.cz; ivana.barcakova@vsb.cz; martin.mensik@vsb.cz; \\ jaroslav.slacala@vsb.cz; j.david@vsb.cz;pavel.svec@vsb.cz;
}

\section{https://doi.org/10.37904/metal.2021.4294}

\begin{abstract}
The paper deals with the issue of decision support in maintenance management and its optimization. Today, there are many modern tools and methods to optimize operational operations and maintenance itself. The aim of the paper is to describe the creation of a technical and economic model of metallurgical equipment for the optimization of preventive maintenance. At present, attention is paid mainly to technical parameters, in contrast to economic indicators. Maintenance costs make up a large part of the operating costs of most manufacturing companies. Maintenance is often considered an economic burden, which only consumes considerable funds and does not create any on its own. Based on the reliability analysis of the data obtained in this way, a reliability model of the given production unit will be created, enabling in the on-line mode the prediction of the technical condition of the metallurgical equipment and possibly their defined machine nodes. The application of artificial intelligence methods will create software tools for computer support of organization and maintenance management, for operational production management in connection with systems for spare parts warehouse management, etc. The principle of the model will be demonstrated on the strategy of periodic preventive maintenance. The so-called combined approach will be applied for the solution of the model and the subsequent optimization of maintenance, which means that not only artificial intelligence methods are used to solve a certain problem, but a connection with some other method.
\end{abstract}

Keywords: Metallurgy, maintenance control, neural-genetic system,

\section{INTRODUCTION}

Industry and the economy as a whole are undergoing fundamental changes due to the introduction of information technology, cyber-physical and artificial intelligence systems in manufacturing, services and all sectors of the economy. The impact of these changes is so fundamental that they are referred to as the 4th Industrial Revolution (Industry 4.0). At the heart of this revolution is the connection between the virtual and cyber worlds and the world of physical reality. This brings with it significant interactions of these systems with the whole society, i.e. with the social world. From the point of view of modern systems theory, in connection with the 4th Industrial Revolution, there is talk of a cyber-physical-social-social revolution, which causes the interconnection of these systems. [1]

It is not just a matter of technology and technical means. A significant change is the approach to the current concept of industrial automation. The expected benefits are based on new possibilities of creating added value made possible mainly by the use of data from interconnected systems and increased capabilities of automated decision-making mechanisms in industrial practice. From the point of view of companies, we can expect an increase in productivity and production efficiency, but also a reduction in the energy and raw material intensity of production.[2],[3] 
The area of machine and equipment maintenance offers a wide range of applications in the field of data analytics. These are analyses of data from production systems and sensors, where, thanks to the modelling of the dependencies of individual parameters, it is possible to identify fault conditions that lead to a reduction in performance or technology failure before they occur. The outputs of these analyses should then enter into preventive and predictive maintenance plans in relation to the maintenance strategy.

The above is also related to a new form of management and that is innovation management, which is a process of rational management of innovations and reflects the needs of both the customer and the manufacturer. Innovation management can be simply used to describe the processes of change management in the company structure. The starting point for increasing the efficiency of complex decision-making processes is the transition to decision-making, which is based on exact, scientific foundations. To increase accuracy means to use modelling and modern problem-solving methods. Modelling is the basic methodological basis for solving complex problems, the application of modern methods in the implementation of individual phases of the model is then a basic condition for its successful implementation. The introduction should provide a clear statement of the study, the relevant literature on the study subject and the proposed approach or solution.

\section{SPECIFICS OF MAINTENANCE OF METALLURGICAL EQUIPMENTS}

Maintenance of metallurgical equipment represents a specific management task, where the share of work, unlike most production activities, changes in both volume and variability over a short period of time. The result is a lower average utilization of employees, which adversely affects the company's economy. Maintenance affects the economy of a metallurgical enterprise in three ways: the duration of repairs directly affects the time utilization of production units, the quality of repairs determines the performance but also the time utilization of production equipment and thus production volume and finally maintenance significantly burdens production costs and significantly affects labor productivity.

The issue of maintenance optimization is a multidimensional decision-making process that depends on the specific properties of the equipment, type, scope and frequency of maintenance operations. The frequency of maintenance interventions is conditioned on the one hand by a qualitatively objectively stochastic course of wear of individual parts of the equipment and on the other hand it is influenced by the extent and especially the moment of preventive maintenance interventions.

The existing, so far generally used in metallurgy and a priori determined basic quality indicators (e.g. service life characterized by the number of cycles) are also significantly insufficient for evaluating, predicting and comparing the reliability of individual objects, and especially for monitoring the development of their quality, measures in production, maintenance, etc. It can be assumed that during long-term monitoring of metallurgical machinery and equipment and the resulting analysis of operating results, the course of basic reliability characteristics for most nodes and components will be significantly more complex than, for example, conventional bath curve of electronic components. that it will change not only with the operating time, but also with the repair and maintenance regime.

When evaluating the reliability of metallurgical systems, the reliability of these systems will be significantly affected by the environment of the systems (i.e. the influence of climatic conditions, operating environment, quality of service, maintenance system, etc.). The results of laboratory tests and experiments of individual parts of the equipment in test rooms are valuable and often irreplaceable for comparison and analysis of the results of performed procedures, but they are difficult to use in their own operation.

Basic statistical material must therefore be obtained from typical types of operation, and difficulties may be caused by unambiguous characteristics of the operating conditions. The methodology of monitoring and evaluation of metallurgical equipment is characterized by the following differences compared to the commonly used procedures in electronics: 
- Most of the monitored components or nodes are repairable, while the degree of repair is directly dependent on the operational and technical consequence of the failure.

- In the event of the occurrence of a larger number of monitored components in the repairable system, the exact moment of failure of a specific element is usually not known with the time lag - during evaluation.

- $\quad$ Troubleshooting with relatively small operational consequences is often carried out only after their accumulation, usually during regular maintenance.

- It is almost impossible for operational, economic or organizational reasons to ensure the monitoring of the reliability of medium and complex systems on homogeneous, statistically sufficiently large files, therefore it is always necessary to take into account a larger variance and perform its technical analysis.

- Varying degrees of integration of the assessed product into a higher technological system, the overall reliability of which is affected on the one hand, and on the other hand is affected by failures of this system; from this point of view, different concepts of fault categorization, their definition and assessment of their consequences usually follow.

- Different assessment of the states of the monitored product (for some products an approach characterized by distinguishing between fault-free and fault states is sufficient; for others, however, this distinction is too rough and multi-state models must be taken into account.

- Various structural divisions of products and expected details of analyzes e.g., failure of its nodes and components.

- Unequal means of experimental determination or verification of reliability indicators of specific products,

- The overall diversity of maintenance and repair systems of the manufacturer and user (this often requires a specific definition of repairability or non-repairability of the product, but also affects the issue of code lists of basic terms, depth of analysis and related technical characteristics and relevant definitions).

It follows from the above that one of the ways to prevent these failures and thus unplanned outages in production is to perform an ongoing assessment of the technical condition. This assessment provides basic input information to determine the probable point in time at which a facility will fail and need to be restored (perform replacement, maintenance, or repair). Above all, knowledge of this moment makes it possible to decide when and to what extent a recovery will need to be carried out and thus mitigate the effects of the impending failure, i.e.

- $\quad$ Carry out recovery preventively outside the shift period and thus prevent downtime.

- $\quad$ Carry out recovery preventively in order to prevent the occurrence of an emergency failure and at the same time to prevent the occurrence of subsequent failures.

- $\quad$ Prepare organizationally and technically in time for the elimination of the fault.

Determining this value represents a complicated problem of a technical-economic nature resulting from the following facts:

- The instantaneous rate of changes in the technical condition of functional surfaces in operation has the character of a random variable.

- Only a prediction based on probability can be made about the level of technical condition of the functional area at a certain moment.

- All quantities and parameters based on or dependent on the rate of change of the technical state have the character of randomly variable quantities.

If we start from the assumption that the technical condition of the building is expressed by the selected diagnostic signal, it is a basic question important for the area of reliability and recovery - when, i.e. at what value of the diagnostic signal, the recovery should be performed. Of course, the answer is that the moment of 
recovery should be optimal, i.e. the technical state for recovery must be determined using the optimal value of the diagnostic signal, i.e. the problem of optimization criteria arises.

It is also directly related to the following issues:

- how to determine the specific value of security requirements,

- what size the limits of the set parameters should be,

- how much is the allowable reduction in operational efficiency,

- $\quad$ which is the need to overhaul, etc.

The current system of maintenance of metallurgical equipment is usually based on the performance of regular preventive maintenance supplemented by data from prophylactic inspections of equipment. These are performed at regular intervals, the length of which is determined by the degree of threat to the entire production process by the equipment or parts thereof. [4] The results of these inspections are recorded in the inspection reports and, on the basis of this information, additional preventive maintenance interventions are planned, with the aim of preventing operational failures and production downtime. Furthermore, faults and downtimes on individual devices are recorded daily. These data serve, among other things, as inputs for evaluating the effectiveness of maintenance. [5] The improved system will use the existing organizational structure of maintenance of metallurgical plants, but will change its management system.

\section{MAINTENANCE MANAGEMENT USING A NEURO-GENETIC SYSTEM}

The solution is based on a classical approach to this issue, e.g. [6], [7] where the basic step is to determine the moment of renewal for elements of complex objects, understood in this case in isolation, with temporary neglect of mutual states and connections with other system elements. This means that each element of the structural model of the device is considered for a given step as a separate system at a given resolution level.

Because the time point of preventive maintenance is a random variable, we can consider the renewal as a stochastic process and in determining the optimal time interval of preventive maintenance based on the mean number of renewals $H(t, u)$ in the interval $(0 ; t)$ at the maintenance interval $u$ (see Equation 1)

$H(t, u)=E[v(t, u)]$

where:

$v \quad$ is $\quad$ the number of faults in the interval $\langle 0 ; t\rangle$ in the maintenance interval $u$,

and from the cost criterion for medium maintenance costs in the form from Equation 2.

$C(u)=c_{1} \cdot H_{1}(t, u)+c_{2} \cdot H_{2}(t, u)$

where:
C(u) are
the mean maintenance costs at the maintenance interval $u$,
$c_{1}$ is the average maintenance cost of one broken element,
$H_{1}(t, u)$ is the function of recovery of the broken element at time $t$ at the maintenance interval $u$,
$c_{2}$ are the average maintenance costs of one intact element,
$\mathrm{H}_{2}(t, u)$ is the intact element recovery function at time $t$ at maintenance interval $u$.

The consequence of such an approach is the optimization criterion (see Equation 3), which results in a discrete value of the preventive maintenance interval at which the renewal of the element is optimal (economically most advantageous).

$C\left(u^{*}\right)=\min C(u)$ for $u>0$ 
where $u^{*}$ is the optimal maintenance interval,

$u \quad$ is the maintenance interval.

To optimize maintenance based on the technical and economic model, it is necessary to monitor the following usually cost items, but also other indicators [8], [9]:

- $\quad$ maintenance costs after failure (Nup) - costs for failures, holding stocks of spare parts and materials (hereinafter NDM), production losses, environmental impacts, safety, maintenance readiness),

- $\quad$ costs of preventive maintenance $(\mathrm{Npu})$ - costs of maintenance planning and NDM, costs of own preventive maintenance without costs of dependent failures, holding spare parts, production losses, environmental impacts, safety, maintenance readiness),

- $\quad$ losses due to maintenance after failure (Zup) - consequence of failure - undesirable phenomenon (see Equation 4).

Zup $=N u p-N p u$

- $\quad$ operating time until blunt fault,

- $\quad$ probability of failure $\mathrm{F}(t p u)$ depending on the time (predetermined interval) of operation to preventive maintenance tpu,

- $\quad$ unit costs for diagnostics, etc.

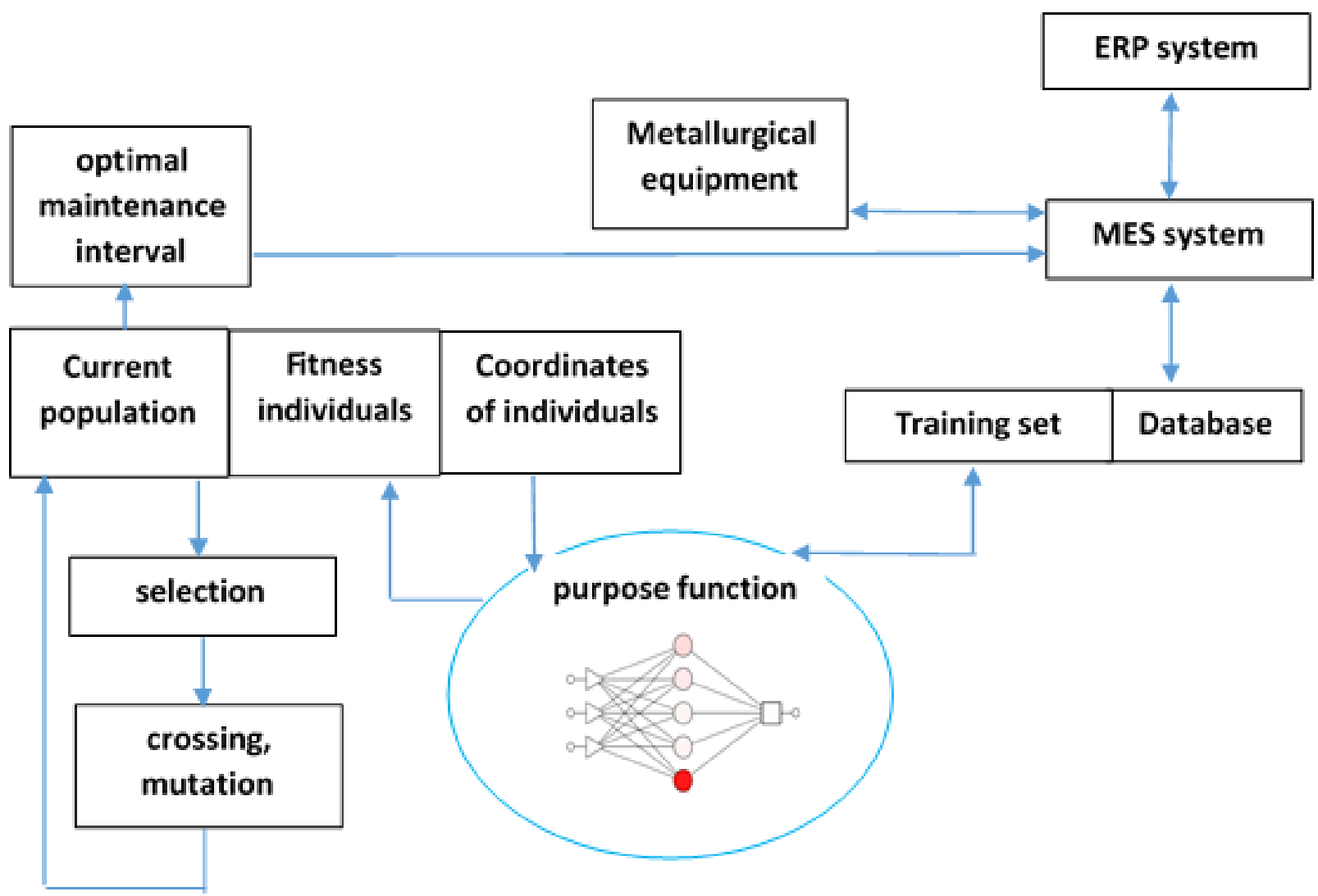

genetic part

neural part

Figure 1 The structure diagram of such a neuro-genetic system 
As a model of optimization of preventive periodic maintenance by the technical-economic model, a specialpurpose function in the form of unit costs for periodic maintenance is used.

The proposed technical and economic model of equipment maintenance optimization has the character of a stochastic probabilistic neuro-genetic resp. neuro-evolutionary system.

The core of the model is a neuro-genetic system to support process control using the capabilities of a neural network and the optimization capabilities of a genetic (evolutionary) algorithm solving a global optimization problem. The function of the purpose function of this system is performed by the neural part of the system in the form of a multilayer network of perceptron character.

The structure diagram of such a neuro-genetic / neuro-evolutionary system is shown in Figure 1.

\section{CONCLUSION}

Using artificial intelligence methods, a solution to the global optimization problem will be created with the help of a neuro-genetic system that uses the capabilities of a neural network and the optimization capabilities of a genetic (evolutionary) algorithm. This neuro-genetic system uses the advantages of both of these methods of artificial intelligence, where the neural network is able to predict future values, i.e. prediction of the required values (states) and the genetic algorithm is then suitable for solving the optimization problem. In this case, it will be possible to predict future values from both operational and economic data using a neuro-genetic system. This calculation will serve as an input purpose function of the genetic algorithm, which then optimizes these predicted results.

\section{ACKNOWLEDGEMENTS}

\section{The work was supported by the specific university research of Ministry of Education, Youth and Sports of the Czech Republic No. RPP2021/50 and SP2021/71 and SP2021/23.}

\section{REFERENCES}

[1] DAVID, J., SVEC, P., GARZINOVA, R., KLUSKA-NAWARECKA, S., WILK-KOLODZIEJCZYK, D., REGULSKI, K. Heuristic modeling of casting processes under the conditions uncertainty. Archives of civil and mechanical engineering. [online]. 2016, vol. 16, no. 2, pp. 179-185. Available from: https://doi.org/10.1016/i.acme.2015.10.006.

[2] AN, Y., CHEN, X., ZHANG, J., LI, Y. A hybrid multi-objective evolutionary algorithm to integrate optimization of the production scheduling and imperfect cutting tool maintenance considering total energy consumption. Journal of Cleaner Production. 20 September 2020, vol. 268, 121540.

[3] BURIAN, P. Internet inteligentních aktivit. Praha: Grada Publishing, 2014.

[4] COMPARE, M., MARTINI, F., ZIO, E., Genetic algorithms for condition-based maintenance optimization under uncertainty. European Journal of Operational Research. 16 July 2015, vol. 244, no. 2, pp. 611-623.

[5] LEGÁT, V., CINDR, P. Využití ukazatelů spolehlivosti k minimalizaci nákladů na údržbu. Praha SNTL, 2006.

[6] HAVLÍČEK, J. Provozní spolehlivost strojů. Praha: Státní zemědělské nakladatelství, 1989.

[7] BARLOW R.E., PROSCHAN F. Statistical Theory of Rehability and Life Testing: Probabihty Models, Silver Spring (1975) où sa version initiale Mathematical Theory of Rehability, J. Wiley,1965.

[8] LEGÁT, V. Management a inženýrství údržby. Druhé doplněné vydání. Praha: Kamil Mařík - Professional Publishing, 2016.

[9] VDOLEČEK, F. Technická diagnostika v systémech údržby. Automa [Online] 2008 [viewed: 2021-01-24]. Available from https://www.automa.cz/cz/casopis-clanky/technicka-diagnostika-v-systemech-udrzby$\underline{2008 \quad 05 \quad 37313 \quad 5634 /}$ 